\title{
The Anesthetic Effects of Clove Oil and MS-222 on Far Eastern Catfish, Silurus asotus
}

\author{
†n-Seok Park \\ Division of Marine Bioscience, College of Ocean Science and Technology, Korea Maritime \& Ocean University, \\ Busan 49112, Korea
}

\begin{abstract}
The objective of this study is to evaluate the anesthetic effects of clove oil and tricaine methanesulfonate (MS222) on the Far Eastern catfish, Silurus asotus, by measuring the times to anesthesia and recovery. Each anesthetic effect of clove oil and MS-222 was tested in two groups of fish with different body sizes: a group of small fish (mean body length: $15.5 \pm 1.58 \mathrm{~cm}$, mean body weight: $50.1 \pm 5.91 \mathrm{~g}, \mathrm{n}=20$ ) and a group of large fish (mean body length: $31.5 \pm 4.19 \mathrm{~cm}$, mean body weight: $302.1 \pm 15.22 \mathrm{~g}, \mathrm{n}=20$ ). The anesthetics were used at concentrations of 200, 300, 400, 500, and $600 \mathrm{ppm}$. The results showed significant relationships between the concentration of the anesthetic and the body size of the fish. Each of these variables showed statistical significance $(p<0.05)$. The time to anesthesia decreased linearly with increasing concentration in the large fish for both clove oil and MS-222 ( $p<0.05)$. Based on an optimal anesthetic time of approximately 1 min, the preferred concentrations of the anesthetics were $500 \mathrm{ppm}$ for clove oil and $600 \mathrm{ppm}$ for MS-222. Both the anesthetic time and the recovery time were shorter for the small fish than for the large fish $(p<0.05)$. Our study showed that the smaller-sized Far Eastern catfish was more easily anesthetized and recovered more rapidly from anesthesia than the larger-sized fish.
\end{abstract}

Key words : Anesthetic effects, Clove oil, Far Eastern catfish, MS-222, Silurus asotus

\section{INTRODUCTION}

Far Eastern catfish, Silurus asotus, is a member of the typical freshwater Siluridae, and an important commercial catfish in Korea (Kim et al., 1988). The fish is warm water fish so it inhabits $20-27^{\circ} \mathrm{C}$ and it lives soft ground (Yang et al., 2015). And the fish is nocturnal so it active night and it is carnivorous fish so it mostly predates not only crustaceans but also aqatic animals. The fish formerly inhabited rivers in Manchuria, Japan, Taiwan, China and Northeast Asia, and elsewhere; and it is widely distributed throughout freshwater systems (Park \& Im, 2001; Park et al.,
2004, 2017; Gil et al., 2017; Lim et al., 2017). This species is an example of tasty and nutritious food, and has been used as such; it is also widely used in private treatment (Park \& Im, 2001; Park et al., 2004, 2017; Gil et al., 2017; Lim et al., 2017). The skin of the Far Eastern catfish is covered with mucus. It is difficult to handle the fish out of the water because the skin of the catfish is slick (Suzuki et al., 2003).

Anesthesia is commonly used in fisheries for both experimental and practical purposes. It is used primarily to immobilize animals to facilitate the handling process, to save time, and to avoid stressing the animals (Summerfelt

Manuscript received May 16, 2018, Received in revised form October 13, 2018, Accepted April 2, 2019

${ }^{\dagger}$ Corresponding Author: In-Seok Park, Division of Marine Bioscience, College of Ocean Science and Technology, Korea Maritime \& Ocean University, Busan 49112, Korea. Tel: +82-51-410-4321, Fax: +82-51-404-4750, E-mail: ispark@kmou.ac.kr

This is an Open Access article distributed under the terms of the Creative Commons Attribution Non-Commercial License (http:// creative-commons.org/licenses/by-nc/3.0) which permits unrestricted non-commercial use, distribution, and reproduction in any medium, provided the original work is properly cited. 
\& Smith, 1990; Gil et al., 2016; Park et al., 2017). Among its principal uses, anesthesia facilitates the following operations: weighing and measuring; marking and tagging; studying fish physiology and behavior; performing surgery; collecting fish in tidal pools and with scuba; photography; preparing fish for live shipment and transport; manually spawning; injecting vaccines and antibiotics; and collecting blood and other tissues (Park et al., 2011; Gil et al., 2016). Anesthesia can decrease the stress levels in fish subjected to blood sampling, immobilization, handling, the injection of vaccines and antibacterial substances, medical treatment for diseases, artificial spawning, transport, and sorting (Park et al., 2011, 2017).

Considerations of toxicity (safety to users and to fish), efficacy, price, the regulations for use, and the purpose of using anesthesia influence the choice of an ideal anesthetic. This ideal anesthetic should have the following characteristics: (1) anesthesia time within $3 \mathrm{~min}$ and recovery time within $5 \mathrm{~min}$; (2) non-toxicity to the fish; (3) ease of use and non-toxicity to the user; (4) absence of effects on the physiology and the movement of the experimental fish; (5) excretion of the anesthetic from the body so that no withdrawal period is required; (6) absence of accumulation effects from repeated administration of anesthesia and absence of side effects; and (7) cost-effectiveness (Park et al., 2003; Gil et al., 2016; Park et al., 2017). Traditionally, chemicals (e.g., urethane, ether and chloroform) were used to anesthetize fish. However, these substances are now restricted because they all contain carcinogens (Hasler \&

Meyer, 1942).

Currently, tricaine methanesulfonate (MS-222) is widely used to anesthetize fish, including food fish. However, it is considered mildly toxic as an edible anesthetic according to the US Food and Drug Administration (FDA), which requires that fish treated with MS-222 undergo an obligatory 21-day withdrawal period (Summerfelt \& Smith, 1990; Park et al., 2017). The active ingredient of clove oil is eugenol (4-allyl-2-methoxyphenol). It is generally used as an analgesic and disinfectant in dentistry and as an additive in perfumes (Park et al., 2008). It is an inexpensive, safe anesthetic and has been used as a substitute for such traditionally employed compounds as MS-222 (Seol et al., 2007; Gil et al., 2016). Moreover, clove oil has been evaluated as safe, inexpensive, non-toxic in the environment, and requiring no withdrawal period compared with other anesthetic chemicals (Park et al., 2008, 2017; Gil et al., 2016). Listed by the US Food and Drug Administration (1978), it has been experimented in fish at different stage including fry to adult fish. It is an excellent sedative anesthetic for long period transportation (Park et al., 2018). Clove oil has been studied as an anesthetic toward a number of species (Endo et al., 1972; Hikasa et al., 1986; Soto \& Burhanuddin, 1995; Keene et al., 1998; Waterstrat, 1999; Chanseau et al., 2002; Coyle et al., 2005; Waterstrat, 2005; Seol et al., 2007). The aim of this study was to determine the optimum concentrations of anesthetic clove oil and anesthetic MS-222 toward Far Eastern catfish. We also investigated the dependence of the anesthetic effects on the size of the fish.

\section{MATERIALS AND METHODS}

The production of Far Eastern catfish, Silurus asotus was executed according to the methods of Kim et al. (2001) and Seol et al. (2008). Mature females were induced to spawn using a single intraperitoneal (IP) injection of human chorionic gonadotropin (hCG, Sigma, USA) administered at 1,000 IU per $\mathrm{kg}$ of body weight $(\mathrm{kg} / \mathrm{BW})$. Sperm was obtained by incising surgically removed testes that had also been given an IP injection of hCG at $500 \mathrm{IU}$ $\mathrm{kg} / \mathrm{BW}$. The eggs were fertilized with sperm diluted in saline using the wet method (Kim et al., 2001; Seol et al., 2008). The eggs were left to fertilize for $5 \mathrm{~min}$, after which they were rapidly rinsed to remove excess sperm. The size of catfish used in anesthesia were sourced from 1-year-old hatchlings with an average body mass of $302.1 \pm 15.22 \mathrm{~g}$ 
(mean $\pm \mathrm{SD}$ ) and a standard length of $31.5 \pm 4.19 \mathrm{~cm}($ mean \pm SD) (large-sized) (Fig. 1A). The size of catfish used in anesthesia were sourced from 2-month-old hatchlings with an average body mass of $50.1 \pm 5.91 \mathrm{~g}($ mean \pm SD) and a standard length of $15.5 \pm 1.58 \mathrm{~cm}($ mean $\pm \mathrm{SD})$ (small-sized) (Fig. 1B).

The anesthetic experiment began on June 29th, 2018 and ended on August 12th, 2018. We randomly selected 20 specimens from each group, which includes different anesthetic and concentration respectively. The experimental fish were adapted to a $400-\mathrm{L}$ glass tube. The temperature of the water in the tube was controlled so that it was consistent in the temperature of the water in the anesthetic and recovery phases of the experiment. All the fish were fasted for $24 \mathrm{hrs}$ before the study. For the anesthetic experiment, one specimen was randomly selected from the breeding tube with a net. Anesthesia was administered in a $50-\mathrm{L}$ plastic rectangular parallelepiped tube under the control of an aeration system. When the fish were anesthetized in an anesthetic tube, they were immediately moved to the recovery tube. The anesthesia levels and recovery times of the fish were measured by the second using a stopwatch.

The anesthetic effects of clove oil (Sigma, USA, clove oil containing 85\% eugenol) and of MS-222 (Sigma, USA) were investigated at the five concentrations of 200, 300, 400,500 , and $600 \mathrm{ppm}$. The stock solution of clove oil was dissolved in 95\% methanol (Sigma, USA) at a ratio of 1:10. The decision-based table for the anesthetic effect (Table 1) was constructed in agreement with the table in Park et al. (2011). The anesthesia time was measured starting from the time when the fish were placed in the anesthetized water to the time at which the stage A6 state was attained. In this stage, the fish were perfectly sedated, with minimum opercular movements. The recovery time was measured starting from the time when the fish were placed in the recovery water to the time at which the stage R6 state was attained. In this stage, the fish again exhibited normal swimming and responsiveness to visual stimulation (Table 1).

One- and two-way analysis of variance (ANOVA) was used to test the significance $(p<0.05)$ of the effects on the sizes of the experimental fish and the concentrations of both clove oil and MS-222. The differences between the groups were analyzed by ANOVA using the SPSS statistics package (SPSS 9.0, SPSS Inc., Chicago, IL, USA). Multiple comparisons were performed using a Duncan's multi-



Fig. 1. External morphology of Far Eastern catfish, Silurus asotus used in this experiment. Large size and small size samples in this picture had grown 18 months and 2 months after hatched, respectively. (A) large size, (B) small size. 
Table 1. Stages of anesthesia induction and recovery in clove oil and MS-222 efficacy tests performed in Far Eastern catfish, Silurus asotus

\begin{tabular}{ll}
\hline \hline Stage & \\
\hline A1 & Normal swimming; opercular movement and normal general movement \\
A2 & Swimming speed slowed; rolling from side to side \\
A3 & Partial loss of equilibrium; swimming erratic \\
A4 & Complete loss of equilibrium; swimming perfectly inside out; pectoral fin, pelvic fin and dorsal fin \\
A5 & Little sedation; anal fin and tail fin movement stop \\
A6 & Perfect sedation; only opercular movement \\
A7 & Opercular movement ceased \\
& \\
R1 & Resume opercular movement \\
R2 & Preferential movement of pectoral fin and tail fin \\
R3 & Dorsal fin, pelvic fin and anal fin movement \\
R4 & Swimming perfectly inside out \\
R5 & Swimming erratic; recovery of balance \\
R6 & Normal swimming; responsiveness to visual stimuli \\
\hline
\end{tabular}

ple-range test (Ducan, 1955).

\section{RESULTS AND DISCUSSION}

During the anesthetic experiments with clove oil and MS-222, no Far Eastern catfish, Silurus asotus died due to the stress associated with anesthesia. Table 2 shows the parameters describing the anesthesia times for clove oil and MS-222 at each concentration of the two anesthetics and each body size of the experimental fish. The anesthesia time was significantly affected by the body size of the fish and by the concentration of each anesthetic. The time decreased consistently with the concentration of each anesthetic, and needed much anesthesia time for the large fish $(p<0.05)$. The anesthesia time of the large fish decreased as the concentration of clove oil increased $(p<0.05)$. Regarding the function of the concentration of clove oil, the trend in the anesthesia times of the small fish was similar to that of the large fish. Furthermore, the anesthesia time was lower in the small fish than in the large fish at each concentration of clove oil $(p<0.05)$. The trends in the anesthesia times in MS-222 for each fish size were similar to those in the anesthesia times in clove oil for the same fish size.

Table 3 contains the parameters associated with the recovery times for clove oil and MS-222 at each concentration and fish size. The recovery times in clove oil and MS222 showed similar patterns to those of the anesthesia times. The recovery times were significantly affected by the fish size and by the concentration of each anesthetic $(p<0.05)$. At each concentration of clove oil and MS-222, 
Table 2. Effects of clove oil dose and MS-222 on anesthesia in large-sized and small-sized Far Eastern catfish, Silurus asotus*

\begin{tabular}{|c|c|c|c|c|}
\hline \multirow{3}{*}{$\begin{array}{c}\text { Dose } \\
\left(\mathrm{mgL}^{-1}\right)\end{array}$} & \multicolumn{4}{|c|}{ Exposure time (sec) } \\
\hline & \multicolumn{2}{|c|}{ Clove oil } & \multicolumn{2}{|c|}{ MS-222 } \\
\hline & Large size & Small size & Large size & Small size \\
\hline 200 & $173 \pm 26.9^{\mathrm{a}}$ & $85 \pm 19.9^{\mathrm{a}}$ & $235 \pm 18.4^{\mathrm{a}}$ & $119 \pm 21.5^{\mathrm{a}}$ \\
\hline 300 & $103 \pm 6.7^{\mathrm{b}}$ & $57 \pm 3.4^{\mathrm{b}}$ & $170 \pm 23.2^{\mathrm{b}}$ & $77 \pm 13.3^{b}$ \\
\hline 400 & $70 \pm 11.3^{\mathrm{c}}$ & $42 \pm 6.5^{\mathrm{c}}$ & $100 \pm 15.9^{c}$ & $56 \pm 4.5^{\mathrm{c}}$ \\
\hline 500 & $62 \pm 8.7^{\mathrm{d}}$ & $40 \pm 2.7^{\mathrm{d}}$ & $82 \pm 8.7^{\mathrm{d}}$ & $50 \pm 6.1^{\mathrm{c}}$ \\
\hline 600 & $47 \pm 6.2^{\mathrm{e}}$ & $32 \pm 2.0^{\mathrm{e}}$ & $61 \pm 9.2^{\mathrm{e}}$ & $40 \pm 4.2^{\mathrm{d}}$ \\
\hline
\end{tabular}

Two-way ANOVA

\begin{tabular}{|c|c|c|c|c|c|c|c|c|c|c|}
\hline & \multicolumn{5}{|c|}{ Clove oil } & \multicolumn{5}{|c|}{ MS-222 } \\
\hline & $\mathrm{DF}$ & Anova SS & Mean square & $F$-value & $p$-value & $\mathrm{DF}$ & Anova SS & Mean square & $F$-value & $p$-value \\
\hline Dose & 1 & $74,451.0$ & $37,225.5$ & 229.3 & $<0.0001$ & 1 & $376,723.1$ & $188,361.5$ & 190.2 & $<0.0001$ \\
\hline Size & 4 & $344,669.7$ & $68,933.9$ & 554.3 & $<0.0001$ & 4 & $1,489,907.0$ & $297,981.3$ & 300.9 & $<0.0001$ \\
\hline Interaction & 10 & $41,357.9$ & $4,135.7$ & 33.2 & $<0.0001$ & 10 & $63,421.2$ & $6,342.1$ & 6.4 & $<0.0001$ \\
\hline
\end{tabular}

* Each value is the mean \pm SD of a triplicate experiment (total $n=60$ ). Values in the same column not sharing common superscripts are significantly different $(p<0.05)$. Large-sized specimens were sourced from 1-year-old hatchlings with an average body mass of $302.1 \pm 15.22 \mathrm{~g}$ and a standard length of $31.5 \pm 4.19 \mathrm{~cm}$. Small-sized specimens were sourced from 2month-old hatchlings with an average body mass of $50.1 \pm 5.91 \mathrm{~g}$ and a standard length of $15.5 \pm 1.58 \mathrm{~cm}$.

the recovery time was greater for the large fish $(p<0.05)$. As the concentration of clove oil and MS-222 increased, the recovery time decreased in the large-sized fish $(p<0.05)$. As the concentration of clove oil increased, the recovery time decreased in the small fish as well $(p<0.05)$. In contrast, the recovery time of these small fish increased as the concentration of MS-222 increased as well $(p<0.05)$.

To define the concentrations that met the efficacy criteria for anesthesia within $3 \mathrm{~min}$, recovery in $10 \mathrm{~min}$ and no mortality during the experiment (Gilderhus \& Marking, 1987; Son et al., 2001; Park et al., 2003; Gil et al., 2016, 2017), we assessed a range of clove oil concentrations from 200 to $600 \mathrm{ppm}$ and a range of MS-222 concentrations from 300 to $600 \mathrm{ppm}$. We decided that the optimum anesthetic concentration would correspond to an anesthesia time of approximately $1 \mathrm{~min}$ and a rapid recovery by both sizes of fish tested. The optimal anesthetic concentrations of each anesthetic on Far Eastern catfish were 500 ppm in clove oil and $600 \mathrm{ppm}$ in MS-222, respectively. The optimal anesthetic concentrations for other species showing an anesthesia time of approximately $1 \mathrm{~min}$ (albeit under differing experimental conditions) are the following: sockeye salmon, Oncorhynchus nerka, a clove oil concentration of $80 \mathrm{ppm}$ at $9.4^{\circ} \mathrm{C}$; rock bream, Oplegnathus fasciatus, clove oil concentrations of $150 \mathrm{ppm}$ at $24^{\circ} \mathrm{C}$ and $100-125 \mathrm{ppm}$ at $26^{\circ} \mathrm{C}$; kelp grouper, Epinephelus bruneus, clove oil concentrations of $50-100 \mathrm{ppm}$ at $22^{\circ} \mathrm{C}$; marine medaka, Oryzias dancena, clove oil concentrations of $100 \mathrm{ppm}$ at 
Table 3. Effects of clove oil and MS-222 doses on recovery in large-sized and small-sized Far Eastern catfish, Silurus asotus*

\begin{tabular}{|c|c|c|c|c|}
\hline \multirow{3}{*}{$\begin{array}{c}\text { Dose } \\
\left(\mathrm{mgL}^{-1}\right)\end{array}$} & \multicolumn{4}{|c|}{ Recovery time (sec) } \\
\hline & \multicolumn{2}{|c|}{ Clove oil } & \multicolumn{2}{|c|}{ MS-222 } \\
\hline & Large size & Small size & Large size & Small size \\
\hline 200 & $190 \pm 26.2^{\mathrm{a}}$ & $133 \pm 13.2^{\mathrm{ab}}$ & $377 \pm 46.6^{\mathrm{a}}$ & $102 \pm 11.9^{\mathrm{a}}$ \\
\hline 300 & $183 \pm 10.1^{\mathrm{ab}}$ & $131 \pm 14.2^{\mathrm{ab}}$ & $285 \pm 41.6^{\mathrm{b}}$ & $108 \pm 5.5^{b}$ \\
\hline 400 & $179 \pm 10.1^{\mathrm{ab}}$ & $129 \pm 9.4^{\mathrm{ba}}$ & $274 \pm 61.8^{\mathrm{bc}}$ & $109 \pm 8.0^{\mathrm{b}}$ \\
\hline 500 & $173 \pm 8.7^{\mathrm{b}}$ & $129 \pm 13.6^{\text {ba }}$ & $206 \pm 28.4^{c}$ & $113 \pm 9.5^{c}$ \\
\hline 600 & $170 \pm 10.3^{\mathrm{b}}$ & $129 \pm 10.3^{\text {ba }}$ & $204 \pm 29.6^{c}$ & $114 \pm 9.5^{\mathrm{c}}$ \\
\hline
\end{tabular}

Two-way ANOVA

\begin{tabular}{|c|c|c|c|c|c|c|c|c|c|c|}
\hline & \multicolumn{5}{|c|}{ Clove oil } & \multicolumn{5}{|c|}{ MS-222 } \\
\hline & $\mathrm{DF}$ & Anova SS & Mean square & $F$-value & $p$-value & $\mathrm{DF}$ & Anova SS & Mean square & $F$-value & $p$-value \\
\hline Dose & 1 & $1,896.9$ & 379.8 & 2.72 & $<0.0001$ & 1 & $30,475.4$ & $7,618.9$ & 26.1 & $<0.0001$ \\
\hline Size & 4 & $282,359.0$ & $141,179.8$ & $1,011.23$ & $<0.0001$ & 4 & $618,919.0$ & $154,729.7$ & 529.2 & $<0.0001$ \\
\hline Interaction & 10 & $8,707.9$ & 870.7 & 6.23 & $<0.0001$ & 10 & $12,833.4$ & 802.1 & 2.7 & $<0.0001$ \\
\hline
\end{tabular}

* Each value is the mean $\pm \mathrm{SD}$ of a triplicate experiment (total $\mathrm{n}=60$ ). Values in the same column not sharing common superscripts are significantly different $(p<0.05)$. Large-sized specimens were sourced from 1-year-old hatchlings with an average body mass of $302.1 \pm 15.22 \mathrm{~g}$ and a standard length of $31.5 \pm 4.19 \mathrm{~cm}$. Small-sized specimens were sourced from 2month-old hatchlings with an average body mass of $50.1 \pm 5.91 \mathrm{~g}$ and a standard length of $15.5 \pm 1.58 \mathrm{~cm}$.

$26^{\circ} \mathrm{C}$; greenling, Hexagrammos otakii, MS-222 concentrations of $125 \mathrm{ppm}$ at $18^{\circ} \mathrm{C}$; and black rockfish, Sebastes schlegeli, a MS-222 concentration of 100 ppm (Woody et al., 2002; Park et al., 2003; Kim et al., 2005; Park et al., 2008, 2009, 2011). A comparison of the anesthetic effects of clove oil on Far Eastern catfish with that of MS-222 shows that Far Eastern catfish is more sensitive to clove oil than to MS-222. Clove oil immobilizes fish effectively at a lower dose than that of MS-222 that produces the same anesthesia time.

The concentrations of clove oil and the results for the ratio of the recovery time to the anesthesia time by fish size are shown in Fig. 2. The ratio of the recovery time to the anesthesia time increases gradually with the clove oil con- centration for each fish size $(p<0.05)$. At each clove oil concentration, the ratio of the recovery time to the anesthesia time for the small fish was higher than that for the large fish $(p<0.05)$. The concentrations of clove oil and the results for the ratio of the recovery time to the anesthesia time by fish size are shown in Fig. 3. The ratio of the recovery time to the anesthesia time gradually increases with the concentration of MS-222 for each fish size $(p<0.05)$. At each MS-222 concentration, the ratio of the recovery time to the anesthesia time for the large fish was higher than that for the small fish $(p<0.05)$. The difference in this ratio between the large fish and the small fish at each concentration of MS-222 showed an opposite trend of difference in this ratio between the large fish and the small fish 




Fig. 2. Effect of clove oil dose and sample size on recovery time/exposure time ratio among Far Eastern catfish, Silurus asotus. Different letters on the bars indicate statistical significance $(p<0.05)$.

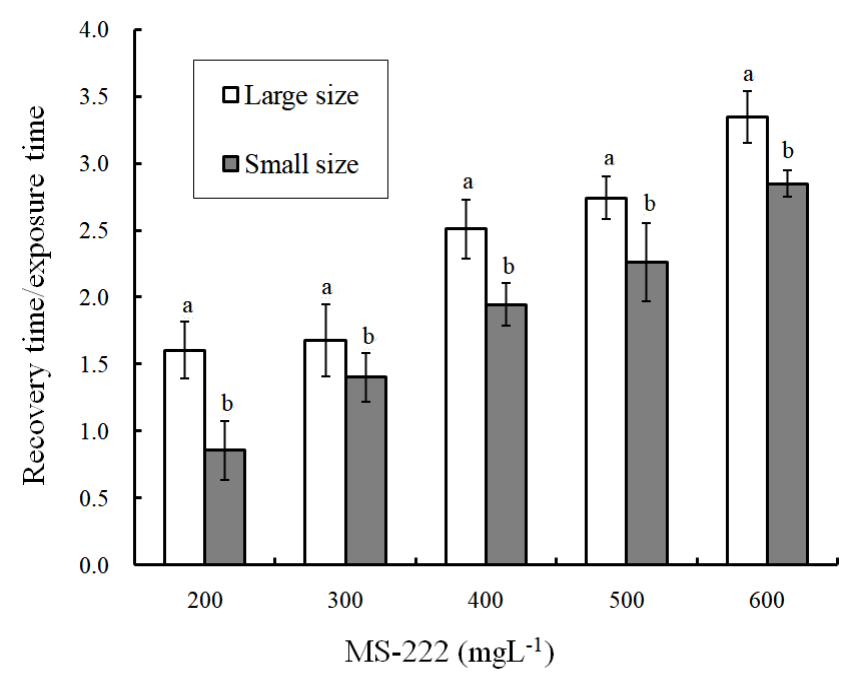

Fig. 3. Effect of MS-222 dose and sample size on recovery time/exposure time ratio among Far Eastern catfish, Silurus asotus. Different letters on the bars indicate statistical significance $(p<0.05)$.

at each concentration of clove oil.

If the ratio of recovery time to anesthetic time is greater than 1.0, the recovery time exceeds the anesthesia time. All of these ratios for clove oil were greater than 1.0. At each concentration, the ratio of recovery time to anesthesia time increases as the anesthesia concentration is increased $(p<0.05)$. That is, the anesthesia time is shortened as the anesthesia concentration increases. In contrast, the anesthetic time increases as the anesthesia concentration is reduced, but the recovery time was relatively shortened $(p<0.05)$. In a similar result reported for rock bream and marine medaka, an increase in clove oil concentration increased the ratio of recovery time to anesthesia time (Park et al., 2009, 2011). For MS-222, all the ratios of recovery time to anesthetic time exceeded 1.0 with the exception of the 200 ppm concentration with small-sized fish. This finding implies that the recovery time is longer than the anesthetic time for MS-222. No other specific rules were inferred from this result.

We found that the small-sized Far Eastern catfish was more sensitive to variations in the concentration of clove oil and MS-222. In addition, the recovery time of smallsized fish is much shorter than that of large-sized fish. Our study shows that the small-sized fish were more easily anesthetized and recovered more rapidly from anesthesia than the large-sized fish. Sockeye salmon resembled Far Eastern catfish in that they showed a significant positive exponential curve in relating the anesthesia time of clove oil to the fish length, and in marine medaka the relationship between the anesthesia time of clove oil and the fish length was similar to that found in Far Eastern catfish (Woody et al., 2002; Park et al., 2011). While our results show that both the anesthesia time and the recovery time increased as the concentration of anesthetics increases, in sockeye salmon only the anesthesia time increased as the clove oil concentration increased. In addition, the lengths of the sockeye salmon used in this study ranged from 400 $550 \mathrm{~mm}$. Therefore, they were all adult fish. Woody et al. (2002) investigated the relationship between the anesthetic concentrations and the lengths of adult fish. We simply referred to the larval fish as the small-size group and the adult fish as the large-size group. In addition to testing the differences in anesthetic effects between larval fish and adult fish, we also investigated the anesthetic effects on different growth stages. This kind of experiment had not 
been conducted in the previous studies.

Our study showed that clove oil and MS-222 are effective at anesthetizing Far Eastern catfish. We also presented the relationship between the anesthetic effect and the size of the Far Eastern catfish. Clove oil and MS-222 meet the requirement of ideal anesthesia (sedative) for Far Eastern catfish in that they offer the anesthesia time within $3 \mathrm{~min}$, they offer a recovery time within $5 \mathrm{~min}$, and both anesthetics are cost-effective, efficient, safe and non-toxic to the fish and the user (Park et al., 2003, 2017; Gil et al., 2016). The results from this study could be useful to aquaculturists and for other purposes that require the sedation of the fish.

\section{ACKNOWLEDGEMENTS}

Comments from anonymous reviewers greatly improved the quality of this manuscript. All experiments in this study complied with the current laws of Korea (the law regarding experimental animals, No. 9932).

\section{REFERENCES}

Chanseau M, Bosc S, Galiay E, Oules G (2002) The use of clove oil as anesthetic for Atlantic salmon (Salmo salar L.) and comparison of its effects with those of 2phenoxyethanol. Bull Fr Peche Piscic 75:579-589.

Coyle SD, Dasgupta S, Tidweel JH, Beavers T, Bright LA, Yasharian DK (2005) Comparative efficacy of anesthetics for the freshwater prawn Macrobrachiurn rosenbergii. J World Aquac Soc 36:282-290.

Duncan DB (1955) Multiple range and multiple $F$ test. Biometrics 11:1-42.

Endo T, Ogishima K, Tanaka H, Ohshima S (1972) Studies on the anesthetic effect of eugenol in some fresh water fishes. Bull Jap Soc Fish 38:761-767.

Gil HW, Goo IB, Park IS (2017) Long-term effects of passive integrated transponder tags in far eastern catfish,
Silurus asotus. Aquacult Eng 79:17-23.

Gil HW, Ko MG, Lee TH, Park IS, Kim DS (2016) Anesthetic effect and physiological response in olive flounder (Paralichthys olivaceus) to clove oil in a simulated transport experiment. Dev Reprod 20:255-266.

Gil HW, Lee TH, Park IS (2017) Effects of cryoprotectants and diluents on the cryopreservation of spermatozoa from far eastern catfish, Silurus asotus. Dev Reprod 21:71-91.

Gilderhus PA, Marking LL (1987) Comparative efficacy of quinaldine sulfate: MS-222 mixtures for the anesthetization of freshwater fish. US Fish Wild Serv Invest Fish Control, p 59.

Hasler AD, Meyer PK (1942) Respiratory responses of normal and castrated goldfish to teleost and mammalian hormones. J Exp Zool 91:391-404.

Hikasa T, Takase K, Ogasawara T, Ogasawara S (1986) Anesthesia and recovery with tricaine methanesulfonate, eugenol and thiopental sodium in the carp, Cyprinus carpio. Nihon Juigaku Zasshi 48:341-351.

Keene JL, Noakes DLG, Moccia RD, Soto CG (1998) The efficacy of clove oil as an anaesthetic for rainbow trout, Oncorhynchus mykiss (Walbaum). Aquacult Res 29:89101.

Kim DS, Bang IC, Chun SK, Kim YH (1988) Effects of the anaesthetic lidocaine on some fishes. Bull Korean Soc Fish Pathol 1:59-64.

Kim DS, Cho HJ, Park IS, Choi GC, Nam YK (2001) Cytogenetic traits and gonad development of induced triploidy in far eastern catfish, Silurus asotus. Korean J Genet 23:55-62.

Kim JH, Hur JW, Park IS, Kho KH, Chang YJ (2005) Effects of the different anesthetic doses of MS-222 and lidocaine- $\mathrm{HCl}$ on the blood physiological responses in black rockfish, Sebastes schlegeli. J Aquacult 18:236244.

Lim SY, Gil HW, Park IS (2017) Change of various characteristics between spawning and non-spawning season 
in diploid and induced triploid Far Eastern catfish, Silurus asotus. Dev Reprod 21:275-286.

Park IS, Gil HW, Lee TH, Nam YK, Lim SG, Kim DS (2017) Effects of clove oil and lidocaine- $\mathrm{HCl}$ anesthesia on water parameter during simulated transportation in the marine medaka, Oryzias dancena. Dev Reprod 21:19-33.

Park IS, Im JH (2001) Determination of the temperaturedependent index of mitotic interval $\left(\tau_{0}\right)$ for chromosome manipulation in Far Eastern catfish, Silurus asotus. Korean J Ichthyol 13:85-88.

Park IS, Im JH, Hur JW (2004) Morphometric characteristics of catfish (Siluridae) in Korea. Korean J Ichthyol 16:223-228.

Park IS, Jo JH, Lee SJ, Kim YA, Hur JW, Yoo JS, Song YC (2003) Anaesthetic effect of lidocaine hydrochloridesodium bicarbonate and MS-222 on the greenling (Hexagrammos otakii). J Korean Fish Soc 36:449-453.

Park IS, Lee TH, Lim SG (2018) Anesthetic efficacy and physiological responses of clove oil on juvenile and adult red spotted grouper, Epinephelus akarra. Fish Aquat Sci 21:25.

Park IS, Park SJ, Gil HW, Nam YK, Kim DS (2011) Anesthetic effects of clove oil and lidocaine- $\mathrm{HCl}$ on marine medak (Oryzias dancena). Lab Animal 40:45-51.

Park MO, Hur WJ, Im SY, Seol DW, Lee JH, Park IS (2008) Anaesthetic efficacy and physiological responses to clove oil-anaesthetized kelp grouper Epinephelus bruneus. Aquacult Res 39:877-884.

Park MO, Im SY, Seol DW, Park IS (2009) Efficacy and physiological responses of rock bream, Oplegnathus fasciatus to anesthetization with clove oil. Aquaculture 287:427-430.

Seol DW, Im SY, Hur WJ, Park MO, Kim DS, Jo JY, Park IS (2008) Haematological parameters and respiratory function in diploid and triploid far eastern catfish (Silu- rus asotus). Genes Genom 30:205-213.

Seol DW, Lee J, Im SY, Park IS (2007) Clove oil as an anaesthetic for common octopus (Octopus minor, Sasaki). Aquacult Res 38:45-49.

Son MH, Park MW, Myeong JI, Kim DJ, Kim BH, Jo QT, Jeon IG (2001) Anaesthetic tolerance of juvenile black rockfish Sebastess schlegeli, produced for wild stock enhancement. Ocean Polar Res 23:285-290.

Soto CG, Burhanuddin (1995) Clove oil as a fish anaesthetic for measuring length and weight of rabbitfish (Siganus lineatus). Aquaculture 136:149-152.

Summerfelt RC, Smith LS (1990) Anesthesia, surgery, and related techniques. In: Schreck CB, Moyle PB (ed), Methods for Fish Biology. American Fishery Society, Bethesda, MD, pp 213-272.

Suzuki Y, Tasumi S, Tsutsui S, Okamoto M, Suetake H (2003) Molecular diversity of skin mucus lectins in fish. Comp Biochem Physiol B Biochem Mol Biol 136:723-730.

United States Food Drug Administration (1978) Scientific Literature Review of Eugenol and Related Substances in Flavor Usage. Flavour Extract Manufactures Association of the United States, Washington, DC, p 1.

Waterstrat PR (1999) Induction and recovery from anesthesia in channel catfish Ictalurus punctatus fingerlings exposed to clove oil. J World Aquacult 30:250-255.

Waterstrat PR, Plnkham L (2005) Evaluation of eugenol as an anesthetic for the American lobster Homerus americanus. J World Aquac Soc 36:420-424.

Woody CA, Nelson J, Ramstad K (2002) Clove oil as an anesthetic for adult sockeye salmon: Field trials. J Fish Biol 60:340-347.

Yang WS, Gil HW, Yoo GY, Park IS (2015) Identification of skeletal deformities in Far Eastern catfish, Silurus asotus under indoor aquaculture condition. Dev Reprod 19:153-161. 